\title{
Direito fundamental a uma nacionalidade
}

\author{
Fundamental right to a nationality
}

Leila Arruda Cavallieri Universidade Veiga de Almeida, UVA, RJ, Brasil

Resumo Os direitos fundamentais são a base da garantia do exercício pleno da dignidade humana. A salvaguarda desses direitos pelo país é um dever que não pode ser relegado ou olvidado. Dessa forma, existem mecanismos que compelem o Estado a proteger, defender e cobrar respeito pelos mesmos por parte da sociedade e de outros Estados. No caso da adoção internacional, o direito à convivência familiar é conquistado pelos adotandos a partir da sentença judicial brasileira. Porém, ao se tornarem filhos de pais domiciliados em outro Estado, as crianças e adolescentes aqui nascidos precisam ter as garantias que são atinentes ao status de cidadão daquele país. A partir do reconhecimento do direito à nacionalidade pelo país de acolhida das crianças, elas passam a usufruir de uma condição de equiparação aos seus adotantes, do ponto de vista de direitos e deveres. A nacionalidade ou a cidadania para os adotandos é um direito fundamental que necessita ser conquistado e preservado, por meio das normativas internas ou de direito convencional, visando atender ao superior interesse da criança ou adolescente. A legislação italiana é uma das legislações estrangeiras que possuem tais dispositivos, o que se torna uma grande conquista no direito transnacional.

Palavras-chave: Direitos fundamentais. Adoção internacional. DiREITO À CONVIVÊNCIA FAMILIAR. DiREITO À NACIONALIDADE.

Abstract Fundamental rights are the basis for ensuring the full exercise of human dignity. The safeguarding of these rights by the country is a duty that cannot be relegated or forgotten. Thus, there are mecha- 
nisms that compel the State to protect, defend and claim respect for them by society and other States. In the case of international adoption, the right to family coexistence is won by adoptees based on the Brazilian judicial decision. However, when they become children of parents domiciled in another State, the children and adolescents here born need to have the guarantees that are pertinent to the status of citizen of that country. From the recognition of the right to nationality by the host country of the children, they will enjoy a condition of equality with their adopters, from the point of view of rights and duties. Nationality or citizenship for adopte is a fundamental right that needs to be won and preserved, through internal norms or conventional law, in order to meet the superior interest of the child or adolescent. The Italian legislation is one of the foreign laws that have such devices, which becomes a great achievement in transnational law.

Key-words: Fundamental Rights. InTERnATIONAL ADOPTION. Right tO FAMILY LIFE. Right TO NATIONALITY.

\section{INTRODUÇÃO}

Todo indivíduo tem direito de viver em uma sociedade que lhe garanta a segurança necessária para o exercício pleno desses direitos, de forma que nada the seja negado e sim oferecido, por força da Constituição, ou de norma estrangeira similar.

Portanto, a exigência da amplitude da proteção e da garantia do exercício deve ser obrigação do Estado, sem que possa haver qualquer negativa de ação.

Sabe-se que isso nem sempre ocorre dessa forma, ainda mais em países com carências básicas e governos desinteressados em saná-las.

Os direitos referidos não configuram uma benevolência ou caridade estatal, são aqueles que fazem parte imprescindível da vida de qualquer pessoa, e que devem ser garantidos por normas jurídicas.

São denominados fundamentais, pois fazem parte do âmago do elenco de prerrogativas que os indivíduos merecem ter ao seu dispor. 
Devem ser respeitados por todos, pois fornecem subsídios para a conquista do ideal da justiça, tanto interna quanto internacional.

Entre as parcelas da população que mais carecem de garantias protetivas relativas aos seus direitos fundamentais encontra-se, sem dúvi$\mathrm{da}$, aquela que concerne à criança e ao adolescente. Por pertencerem a um grupo com intenso grau de fragilidade e vulnerabilidade, devem ser sempre prioridade dos Estados e da sociedade, visando condições de melhoria de suas vidas, até mesmo desde antes de seu nascimento.

Dessa forma, os institutos jurídicos que objetivam proteger crianças e adolescentes necessitam de intenso controle e expansão do universo que abrangem para efetivar essa proteção, já que se constata que a estrutura social em que se encaixam é perversa e descompromissada.

No âmbito do Direito da Criança e do Adolescente, encontra-se o instituto da adoção, tanto em sua perspectiva interna quanto transnacional. O instituto em apreço envolve uma série de pressupostos para a sua concretização, sendo que a busca do superior interesse da criança é a prioridade absoluta.

Em relação à adoção internacional, o cuidado para que o processo tenha um deslinde favorável e exitoso para as partes, priorizando o superior interesse dos adotandos, é essencial. O crescimento num meio familiar caloroso, seguro, protetor, afetuoso, é direito fundamental de todas as crianças, seja em sua família natural ou em uma família substituta.

A autoridade que concede a adoção, por intermédio de sentença ou outro meio lícito que as normativas locais reconheçam, precisa ter pleno conhecimento das leis que serão aplicadas ao adotando no país para o qual será deslocado, com o fim de conviver com a sua família substituta. Também é necessário o conhecimento das normas convencionais internalizadas pelos Estados que aderiram a convenções e tratados sobre adoção e proteção das crianças. Esse conhecimento pode garantir que sejam respeitados direitos fundamentais para a total integração emocional da criança na nova família, com ramificações para a conquista de outros direitos, nas searas civil e política.

Dessa forma, a pesquisa a respeito das medidas concessivas da adoção e do instituto no âmbito internacional é essencial, assim como 
o conhecimento profundo das leis aplicáveis às partes, em especial à dimensão mais vulnerável: a criança ou o adolescente adotado.

Entre os direitos que não podem ser negados ao adotando encontra-se o de usufruir da mesma nacionalidade de seus pais adotivos ou do Estado onde se domiciliará definitivamente, a fim de que possa gozar de todos os efeitos benéficos que a posse dessa nacionalidade incluir.

Assim, o estudo da concessão de uma nacionalidade ao adotando pelas leis do Estado dos adotantes é a base da pesquisa e das conclusões descritas neste trabalho.

\section{A NACIONALIDADE COMO DIREITO FUNDAMENTAL}

A Constituição Federal de 1988 , por meio do $\S 1^{\circ}$. do art. $5^{\circ}$., dispõe que:

$\S 1^{\circ}$. As normas definidoras dos direitos e garantias fundamentais têm aplicação imediata.

Aparentemente, o dispositivo parece claro, mas a dificuldade está em perceber o conceito de direito fundamental e a sua abrangência. Para alguns autores, existe um contrassenso, criado pela própria Constituição. ${ }^{1}$

Apesar disso, pode-se afirmar a relevância expressa constitucionalmente dos direitos fundamentais e sua proteção para a vida em sociedade, à medida que as decisões judiciais passam a delineá-los, o que tem ocorrido cada vez com mais constância. Seus efeitos devem ser sempre maximizados e não impedidos.

1 Segundo a visão de Cláudio Pereira de Souza Neto (2002), existe contradição no texto constitucional, na medida em que estabelece, ao mesmo tempo, a autoaplicabilidade das normas de direitos fundamentais e um instrumento, o mandado de injunção, que pressupõe a existência de prerrogativas inerentes à nacionalidade, cidadania e soberania. Se são autoaplicáveis, não haveria necessidade de um instrumento para viabilizar seu exercício (SOUZA NETO, Cláudio Pereira. Fundamentação e Normatividade dos Direitos Fundamentais: Uma Reconstrução Teórica à Luz do Princípio Democrático. In: Arquivos de Direitos Humanos. Rio de Janeiro: Renovar, 2002, p. 19). 
Os direitos fundamentais necessitam ser tutelados de forma plena para que possam servir a todas as pessoas e nações. Essa tutela também se estende à repressão, por meio de mecanismos apropriados, caso haja violação dos mesmos. Os Estados não podem permitir nem se omitir quando da existência de constatações de que houve ou se anuncia a possibilidade de haver qualquer lesão a esse direito.

Daniel Sarmento (2002) afirma que:

Ademais, há norma expressa que permite a consagração dos deveres de proteção em relação aos direitos fundamentais em geral: trata-se do art. $5^{\circ}$, inciso XLI, da Lei Maior, segundo o qual 'a lei punirá qualquer discriminação atentatória dos direitos e liberdades fundamentais'.2

A Constituição brasileira elege como prioridade, entre outros, o direito da criança e do adolescente conviverem com sua família e com a comunidade da qual fazem parte.

As novas configurações familiares têm ajudado muito no cumprimento do mandamento constitucional, pois a entrega de crianças a famílias de formatação não convencional tem aumentado com frequência.

O legislador infraconstitucional também atentou para a proteção que crianças e adolescentes carecem por parte de todos, Estado e sociedade, formulando no ECA o art. $4^{\circ}$.

Art. $4^{\circ}$. É dever da família, da comunidade, da sociedade em geral e do poder público assegurar, com absoluta prioridade, a efetivação dos direitos referentes à vida, à saúde, à alimentação, à educação, ao esporte, ao lazer, à profissionalização, à cultura, à dignidade, ao respeito, à liberdade e à convivência familiar e comunitária.

2 SARMENTO, Daniel. A Dimensão Objetiva dos Direitos Fundamentais: Fragmentos de uma Teoria. In: Arquivos de Direitos Humanos. Rio de Janeiro: Renovar, 2002, p. 97. 
Os direitos fundamentais possuem eficácia irradiante, pois todo o ordenamento jurídico fica impregnado de seus valores e diretrizes, exigindo dos operadores do Direito levarem sempre em consideração os princípios da dignidade humana e da justiça social em suas interpretações e atividades. ${ }^{3}$

A partir da premissa da relevância de se garantir a todo cidadão direitos que propiciem assegurar sua dignidade e segurança, entende-se que ter proteção de um Estado e a ele ser ligado pelo vínculo político, jurídico e afetivo, concede ao indivíduo, destinatário da norma, as possibilidades de usufruir benefícios e vantagens inerentes a esse status.

Esse liame é político, pois concede à pessoa a possibilidade de participar da vida política do Estado, usando seu direito de votar e ser votado. É também jurídico porque se define por meio de ações legislativas e judiciais, que criam as condições para a sua fruição. A afetividade está ligada ao patriotismo, ufanismo, lealdade e empatia com a nação que representa essa pessoa.

Ainda se pode acrescentar a esses direitos a qualidade de efetividade, pois suas consequências se legitimam pela ação do próprio Estado.

Os momentos históricos, de certa forma, estabelecem parâmetros com base no valor da dignidade humana e daí se descobrem e irradiam direitos fundamentais. ${ }^{4}$

Para Ingo Sarlet (1998), “os direitos fundamentais, ao menos de forma geral, podem ser considerados concretizações das exigências do princípio da dignidade da pessoa humana". ${ }^{5}$

O legislador constituinte de 1988, ao entender que os direitos fundamentais assumem contornos de maior importância na vida dos indivíduos, estabeleceu, no texto da Constituição, o Título II, Dos Direitos

SARMENTO, 2002, p. 80.

4 BRANCO, Paulo Gustavo Gonet. In: MENDES, Gilmar Ferreira; COELHO, Inocêncio Mártires; BRANCO, Paulo Gustavo Gonet. BRANCO, Paulo Gustavo Gonet. Teoria Geral dos Direitos fundamentais. Curso de Direito Constitucional, 4. ed. rev. e atual. São Paulo: Saraiva, 2009, p. 271.

5 SARLET, Ingo. A eficácia dos direitos fundamentais. Porto Alegre: Livraria do Advogado, 1998, p. 109. 
e Garantias Fundamentais. Esse Título dividiu-se em Capítulos. Exatamente o Capítulo III dispôs sobre a nacionalidade.

Como direito fundamental da pessoa, define o rol de direitos e deveres e o regime jurídico do indivíduo.

É um dos direitos que não podem ser minimizados nem olvidados, pois que garante a ligação do indivíduo com um país por meio da condição de nacional. É um vínculo que apresenta concessão de direitos e exigência de cumprimento de deveres.

Celso de Albuquerque Mello (2001, p. 929) identifica dois diferentes sentidos para conceituar nacionalidade. O autor explica que há o sentido jurídico, onde o Estado tem o papel preponderante, dando ao indivíduo a qualidade de seu membro. O outro sentido é o sociológico, pois um grupo de pessoas se une pelo idioma ou raça ou religião, e exprime um desejo de estarem juntos. ${ }^{6}$

Pode-se entender que é a mesma acepção do que se denomina vínculo afetivo.

No âmbito convencional, vários instrumentos que o Brasil ratificou e internalizou demonstram a dimensão da relevância do exercício do direito de ser nacional.

O Pacto Internacional sobre Direitos Civis e Políticos, internalizado pelo Brasil pelo Decreto $n^{\circ}$. 592, de 6 de julho de 1992, estabelece em seu art. 24 que:

“3. Toda criança terá o direito de adquirir uma nacionalidade".

O mesmo princípio é reiterado pela Convenção Interamericana de Direitos do Homem, Pacto de San José da Costa Rica, promulgado no Brasil pelo Decreto $n^{\circ} .678$, de 6 de novembro de 1992, estabelece que:

Art. 20 - Direito à nacionalidade

1. Toda pessoa tem direito a uma nacionalidade.

6 MELLO, Celso D. de Albuquerque. Curso de Direito Internacional Público. Rio de Janeiro: Renovar, 2001. 
2. Toda pessoa tem direito à nacionalidade do Estado em cujo território houver nascido, se não tiver direito a outra.

3. A ninguém se deve privar arbitrariamente de sua nacionalidade, nem do direito de mudá-la.

Diante das normativas convencionais, aliado ao que dispôs o legislador constituinte, percebe-se que usufruir de uma nacionalidade é um direito fundamental que a ninguém deve ser negado.

A concessão de nacionalidade, no Brasil, é direito discricionário do Estado, após cumprimento dos requisitos constitucionais. Cada Estado define quem é seu nacional e, por exclusão, quem não se adéqua às exigências legais, será considerado estrangeiro ou apátrida.

Um dos critérios utilizados pelos legisladores para aferição de nacionalidade a alguém é o sistema do ius solis (direito do solo, do território). Quem nasce em certo território, como regra geral, é nacional do Estado que o território representa. É o caso da lei brasileira.

A Constituição Federal estipula no art. 12 que:

Art. 12. São brasileiros:

I - natos:

os nascidos na República Federativa do Brasil, ainda que de pais estrangeiros, desde que estes não estejam a serviço de seu país;

Dessa feita, crianças ou adolescentes nascidos no Brasil são brasileiros natos, com exceção daqueles cujos pais estejam a serviço de seu país.

Florisbal Del'Olmo ${ }^{7}$ (2015) se refere ao caso de brasileiros que podem ter duas nacionalidades primárias, uma pelo ius soli, no caso das crianças aqui nascidas e outra pelo ius sanguinis e isso independe de

DEL'OLMO, Florisbal de Souza. A releitura da perda da nacionalidade brasileira nata à luz do caso Claudia Hoerig. In: RAMOS, André de Carvalho (Org.). Direito internacional privado: questões controvertidas. Belo Horizonte: Arraes Editores, 2015. 
sua vontade ou de seus pais. Pode ocorrer pelo registro civil ou outro procedimento administrativo equivalente. ${ }^{8}$

Diante das premissas elencadas, a afirmação de que crianças nascidas no Brasil são brasileiras, estando com suas famílias ou abrigados em instituições de acolhimento, é constitucional. Todas são brasileiras natas.

\section{COMPREENDENDO A ADOÇÃo INTERNA E A INTERNACIONAL}

O tema que tem relevo neste trabalho é concernente à nacionalidade da criança ou adolescente nascida(o) e residente no Brasil que é sujeito de uma adoção internacional. Nesses casos, a família adotante reside ou se domicilia em outro país.

Entende-se ser o direito a compartilhar a nacionalidade da nova família ou manter a que já possui um direito fundamental que exige proteção integral.

Importante, então, faz-se o conhecimento desse instituto, a adoção transnacional, envolvendo partes com domicílios distintos. Sua eficácia não pode ser mensurada apenas pelas decisões das autoridades que atuam na consecução da medida adotiva.

A adoção internacional é uma forma de colocação da criança ou adolescente, residentes no Brasil, em família substituta, residente ou domiciliada em outro país. ${ }^{9}$

8 O sistema do ius sanguinis ou direito da filiação, a princípio, não se aplicaria aos casos de adoção internacional no Brasil pois se refere a nascidos no exterior, filhos de brasileiros. O art. 12, I dispõe: b) os nascidos no estrangeiro, de pai brasileiro ou mãe brasileira, desde que qualquer deles esteja a serviço da República Federativa do Brasil; c) os nascidos no estrangeiro de pai brasileiro ou de mãe brasileira, desde que sejam registrados em repartição brasileira competente ou venham a residir na República Federativa do Brasil e optem, em qualquer tempo, depois de atingida a maioridade, pela nacionalidade brasileira.

9 A colocação em família substituta pode se dar pela guarda, tutela ou adoção, sendo esta a que traz mais benefícios para o adotando, de acordo com o art. 28 do Estatuto da Criança e do Adolescente (Art. 28. A colocação em família substituta far-se-á mediante guarda, tutela ou adoção, independentemente da situação jurídica da criança ou adolescente, nos termos desta Lei). 
É medida excepcional que só deve ser concedida quando não houver qualquer família aqui residente interessada em postular a adoção. ${ }^{10}$

Sem dúvida alguma, não há sentido em se deslocar para o exterior uma criança ou adolescente que possa ser colocado em família substituta no Brasil, mantendo sua cultura, hábitos, religião, idioma e personalidade.

A ausência de regulamentação legal da medida ocasionou muitos desacertos para as crianças e os adotantes. É provável que várias adoções de caráter transnacional tenham ocorrido no Brasil, sem que tenha sido do conhecimento de qualquer autoridade judicial. Isto se explica pelo fato de o Código Civil de 1916 não mencionar a adoção internacional e não submeter as nacionais a controle judicial e sim, a um tabelião. Portanto, qualquer pessoa poderia ir a um cartório para realizá-la. Os pais ou representantes legais, caso quisessem, não eram impedidos de entregar seu filho ou representado a quem desejassem. Era lavrada uma escritura de adoção ${ }^{11}$ e se a pessoa adotante residisse fora do país, levava para o exterior a criança ou o adolescente sem maiores entraves. Apesar de o Código Civil ter se restringido à adoção nacional, isto não significava que o instituto destinava-se apenas a adotantes brasileiros. Era também utilizado por famílias residentes fora de nosso território, por meio da adoção mediante simples escritura pública. ${ }^{12}$

A escritura pública da adoção era formalizada e registrada no registro civil das pessoas naturais. Esse documento não trazia informações sobre a origem do adotando, muito menos a respeito das famílias que pleiteavam as adoções. $O$ controle era inexistente, tanto se a adoção

10 Essa recomendação, mesmo antes de haver normativas que a endossassem, era utilizada pelas autoridades judiciais que concediam a adoção internacional e muito enfatizada por especialistas na matéria, em congressos internacionais. Atualmente, a lei que regula a medida, o Estatuto da Criança e do Adolescente, prevê categoricamente, no art. 51, II, que somente após esgotadas todas as possibilidades da criança ou adolescente ser adotada(o) no Brasil é que esta(e) ficará apta(o) a ir para outro Estado, com a família adotante.

11 Popularmente, dizia-se "dar um filho de papel passado". O papel era a escritura.

12 Assim dispunha o art. 375 do Código Civil de 1916: “Art. 375. A adoção far-se-á por escritura pública, em que não se admite condição, nem termo”. 
fosse nacional quanto internacional. Não se apurava nem se a criança passaria aos cuidados de terceiros e de qual forma isso ocorreria.

Essa forma de adoção cartorária, meramente contratual, apesar de lícita, não garantia benefícios reais para as partes, pois, como explicitado, nem sempre os pais biológicos tinham informações sobre as pessoas que estavam adotando os seus filhos, quer fossem brasileiros ou estrangeiros, residentes no Brasil ou no exterior. E os adotantes pouco sabiam sobre o adotando, sua família biológica, suas dificuldades ou carências.

$\mathrm{O}$ ato de se desligar de um filho é um sofrimento sem igual, sejam quais forem os motivos para que tal ocorra.

Havia casos de mães solteiras no Brasil, sem meios financeiros para se manter, naquela época muito estigmatizadas, que, pressionadas pelo fator social, abriam mão de seus filhos, iam a um cartório e transferiam o poder familiar para outra pessoa, muitas vezes totalmente desconhecida. Algumas mulheres, sob influência temporária do estado puerperal, rejeitavam seus bebês e faziam as adoções. Por ser um estado não permanente, muitas vezes, após medicadas, essas mães adquiriam consciência do que fizeram, se arrependiam, mas não podiam voltar atrás. Desconheciam o destino de seus filhos e não os recuperavam.

Em entrevista concedida pela médica Fernanda Cavallieri, foi explicado que o período pós-parto, também conhecido como puerpério, começa com o nascimento do bebê e saída da placenta. O término desse período não é tão bem definido, mas comumente considera-se de seis a oito semanas após o parto, uma vez que após esse período muitos dos efeitos causados pelo período gravídico já desapareceram, e o estado geral da mulher retornou às condições anteriores à gestação. Não obstante, em alguns estudos o puerpério pode se estender até 12 meses após o nascimento.

Entre as alterações fisiológicas que ocorrem na mulher, esperadas no período pós-parto, podemos destacar: tremores, involução uterina, loquiação, alterações nos níveis hormonais (esteroides sexuais, gonadotrofinas e HCG), lactação mamária, irregularidade do ciclo menstrual, alterações na pele e cabelo, perda de peso, e outros menos comuns. 
A médica prossegue informando que o puerpério também abrange transtornos psiquiátricos específicos desse período, e que podem ser classificados de acordo com sua severidade, do mais brando ao mais grave: disforia puerperal (postpartum blues), depressão pós-parto e psicose pós-parto.

A disforia puerperal tem uma alta prevalência, em até $85 \%$ das mulheres como mostra a maioria dos trabalhos, e trata-se de um quadro leve e transitório, que não impede que a mulher realize suas funções diárias, e usualmente não requer tratamento. A depressão pós-parto tem uma prevalência baixa, em torno de $15 \%$ das mulheres, e pode causar repercussões negativas na vida da mulher e na relação entre mãe e bebê. A psicose pós-parto é rara, com prevalência menor que $0,5 \%$ entre as puérperas, e envolve sintomas psicóticos, havendo risco de suicídio e até infanticídio; e geralmente requer internação hospitalar. ${ }^{13}$

A proteção interna aos menores de idade regulamentou-se aos poucos, mas se manteve contínua. Apesar de grandes intervalos, cada normativa recente trazia mudanças significativas. Nem todas eram elogiadas, mas levavam ao caminho da discussão do tema, que era o necessário.

Por meio do Decreto 5.083, de $1^{\circ}$. de dezembro de 1926, o governo decidiu consolidar as leis de assistência e proteção a menores, acrescentando as normas que o decreto previa ao que já existia no ordenamento jurídico atinente ao assunto. A partir de uma uniformização da linguagem e direcionamento para uma harmonização do conteúdo, ficou estabelecido que a nova lei se denominaria Código de Menores. No contexto do Decreto 5.083, ${ }^{14}$ alguns artigos definiam situações que se assemelhavam em grande parte ao instituto da adoção, utilizando,

13 CAVALLIERI, Fernanda Aquino. Entrevista concedida a Leila Cavallieri em 2015. Fernanda Aquino Cavallieri (CRM 5283292-8) é médica, formada pela Faculdade de Medicina da UNIRIO, possui especialização em Radiologia pela UERJ e é membro do Colégio Brasileiro de Radiologia.

14 Note-se que esse decreto já trazia um arcabouço do que mais tarde se transformaria em adoção judicializada, uma vez que o juiz poderia decretar a perda do poder familiar dos pais biológicos, entregar a criança ou o adolescente a pessoa que se propusesse a educá-la(o), de forma gratuita, e sem que essa pessoa fosse obrigada, depois de um tempo, a devolvê-la(o) para a sua família natural. 
porém, outra terminologia. Os artigos 32,33 e 34 do decreto davam uma ideia do que poderia ser o acolhimento de crianças ou adolescentes por parte de adultos interessados, em especial o art. $34 .{ }^{15}$

Os atos de entrega de um menor a alguém com o fito de educá-lo e sustentá-lo se faziam com a intervenção de uma autoridade judicial. Não se confundia, porém, com a adoção civil prevista no Código Civil de 1916, que prescindia da atuação de um membro do Poder Judiciário nem com a adoção judicial, aquela que mais tarde passaria a se realizar nos Juizados de Menores. Essa designação do juízo, mais tarde, passou a ser Vara da Infância, da Juventude e do Idoso. ${ }^{16}$

Conforme sugerido pelo Decreto 5.083/26, promulgou-se um Código de Menores, em 1927, que passou a fazer parte do ordenamento jurídico brasileiro por força do Decreto $\mathrm{n}^{\circ}$. 17.943-A, em 12 de outubro de 1927. Era uma legislação vista por especialistas como perfeita, sob o ponto de vista conceitual e de sua filosofia. Na época, problemas atuais como miséria, drogas, desrespeito aos direitos das crianças e desin-

15 Os artigos citados apresentavam-se dessa forma:

Art. 32. Quando, pela intervenção do pai, da mãe, do tutor, ou por decisão judicial, o menor tiver sido confiado a alguma das pessoas previstas pelos artigos antecedentes, e o reclamar quem tenha direito, se for provado que o reclamante desinteressou-se do menor desde longo tempo, a autoridade judicial pode, tomando em consideração o interesse do menor, mantê-lo sob a guarda e responsabilidade da pessoa a quem estava confiado, determinando, se for preciso, as condições nas quais o reclamante poderá vê-lo.

Art.33. Nos casos do artigo precedente, a autoridadejudicial pode também, conforme as condiçõespessoaisdopai,oumãe, oututor, quereclamaomenor,decretaraperdadopátrio poder ou a remoção da tutela, concedendo-a a quem o menor está confiado ou a outrem. Art. 34. Esse mesmo preceito é aplicável ao caso em que o responsável pelo menor o entregue a terceiro, para o criar e educar gratuitamente, sem a declaração expressa de lho restituir.

16 A Lei $n^{\circ} .4 .504$, de 11 de janeiro de 2005, alterou o CODJERJ, definindo uma nova nomenclatura para a $1^{\text {a }}$ Vara da Infância e da Juventude, que passou a denominar-se Vara da Infância, da Juventude e do Idoso, com competência para fiscalizar, orientar e apurar irregularidades em instituições e abrigos para idosos, além de garantir medidas de proteção e atendimento à terceira idade. Disponível em: $<\underline{\text { https://por- }}$ taltj.tjrj.jus.br/web/guest/vara-da-infancia-da-juventude-e-do-idosol>. Acesso em $17 / 06 / 2017$. 
formação não eram tão visíveis como se constata na atualidade. Ainda pouco se mencionavam os direitos humanos ou formas de garanti-los. Sua proteção, apesar de registrada, não era eficaz.

Esse conjunto de normas não fazia qualquer referência ao instituto da adoção. Conclui-se, então, que as adoções continuavam a ser feitas sob a égide do Código Civil, da forma como ditava o Decreto 4.827/24, sem atuação judicial. As adoções avançavam concretizando-se por escritura pública, o que impedia o controle e dificultava a apuração dos reais benefícios, como o superior interesse da criança e do adolescente.

Essas adoções podiam ter caráter doméstico ou internacional, e como se conclui, sem qualquer forma de controlar a saída da criança do território brasileiro, pois estava acompanhada de seus novos pais, munidos de toda documentação necessária.

Dessa forma, de posse da escritura de adoção, era tarefa dos adotantes decidir o que fazer com seus filhos adotivos. Não se fazia qualquer acompanhamento a posteriori. Apesar de não ter se referido ao instituto como modernamente é conhecido, o Código de Menores de 1927 preocupou-se bastante com crianças e adolescentes, dispondo regras desde a lactação até o fim da menoridade.

Lemos de Britto (1929) esclarece que quando algum civil ou autoridade policial encontrasse um infante exposto, deveria imediatamente avisar às autoridades judiciais para que essas tomassem providências. Comentando o código, o autor diz que a autoridade judicial podia autorizar que as crianças fossem cuidadas por pessoas que desejassem criá-las. ${ }^{17}$

17 Britto informa: "A lei não fala na obrigação de educação, mas deve subtender-se que o tutor assume o compromisso de educar a criança adotada". Percebe-se que a utilização do termo adotada é resgatado do Código Civil, já que o Código de Menores não se referia à adoção. Britto prossegue: "Pode, mais, o juiz nomear tutores para a criança. Corolário lógico dos dispositivos mencionados, prescreve-se que a pessoa que tomou sob sua tutela, voluntaria ou obrigatoriamente, a criança, não pode transferi-la a terceiro sem consentimento da autoridade pública ou de quem de direito". Nessa continuação do texto, o autor usou o termo tutela. Ele elogiava o Código, considerando-o avançado, até se colocar no mesmo pé das mais adiantadas legislações da época (BRITTO, Lemos. As leis de menores no Brasil. Rio de Janeiro: F. Briguiet e Cia., 1929, p. 39). 
Por meio da lei 3.133, de 1957, que atualizava o instituto da adoção previsto no Código Civil, e modificava seus artigos 368, 369, 372, 374 e 377 , poderia ter havido algum progresso no procedimento, mas a situação permaneceu sem alteração, naquilo que se refere a uma maior cautela em relação às consequências do instituto no destino dos adotandos. Os artigos acabavam propiciando a mesma facilidade para se ter a posse e guarda de uma criança ou adolescente no Brasil. A adoção continuava a ser feita por escritura pública, nos cartórios de registro de pessoas naturais e o texto do art. 375 do CC ficou inalterado. ${ }^{18}$

Porém, a lei apresentava certo aspecto de novidade, já que a adoção passa a ser vista como um ato de assistência aos menores desvalidos. Isto se percebe na constatação de diferença que se fazia, legalmente, entre filhos biológicos, legitimados ou não, e os adotivos. Estes não tinham direito de concorrer à herança de seus pais adotivos em cotejamento com os irmãos, filhos biológicos. A ideia era de que se estava fazendo uma caridade em relação a essas crianças e adolescentes. Porém, com a morte dos pais, em face da existência de irmãos legítimos, eles ficavam desprotegidos legalmente, contando apenas com a generosidade do restante de familiares ou conhecidos para suprir as suas necessidades (Art. 377 CC). ${ }^{19}$

Alyrio Cavallieri (1978) explicava que: “A fim de que haja uma garantia de que a adoção é feita em benefício de menores, mesmo que tenham pais ou responsável, foi sugerido que o ato dependesse, sempre, de homologação por um juiz". ${ }^{20}$

18 O artigo dispunha que a adoção seria realizada por escritura pública.

19 Leila Arruda Cavallieri, explica que: "Quanto à sua saída do país, realmente não era controlada por autoridades, uma vez que, munidos da escritura de adoção, os adotantes, quer brasileiros, quer estrangeiros, eram reconhecidos como pais legítimos e podiam dar a seus filhos o destino que quisessem. Não havia previsão para se verificar o destino e as condições às quais os adotandos eram submetidos a posteriori, tanto no Brasil quanto no exterior, se fosse o caso daquilo que se conhece atualmente por adoção internacional” (CAVALLIERI, Leila Arruda. O Direito Internacional e a Criança. Adoção Transnacional e Nacionalidade do Adotando. Belo Horizonte: Arraes Editores Ltda, 2017, p. 95).

20 CAVAllieri, Alyrio. Direito do Menor, 2. ed. Rio de Janeiro, Freitas Bastos, 1978, p. 87. 
Somente em 1979 um novo Código surgiu e revogou o Código de Menores de 1927. Mas as adoções cartorárias continuaram a ser realizadas, pois não foram proibidas. Elas corriam em paralelo com as então adoções judiciais e também diziam respeito à sua forma internacional.

O Código de Menores de 1979 estabelecia no art. 20 que o estrangeiro residente ou domiciliado fora do país poderá pleitear colocação familiar somente para fins de adoção simples e se o adotando brasileiro estiver na situação irregular, não eventual, descrita na alínea a, inciso I, do art. $2^{\circ}$. dessa Lei. ${ }^{21}$

Os legisladores e os especialistas passaram a se preocupar com a ausência de normativas que regulamentassem com mais precisão a adoção internacional. Percebia-se, inicialmente, que havia uma imprecisão conceitual, envolvendo elementos, ora ligados à nacionalidade das partes, ora ao domicílio.

O art. 20 do Código de Menores de 79 não estabelecia uma definição clara, causando insegurança na aplicação da lei. Podia ser questionado se um brasileiro residente fora do Brasil ou um estrangeiro aqui domiciliado, caso quisessem fazer a adoção de criança ou adolescente aqui residente, seria essa medida de caráter interno ou transnacional. De outra feita, se houvesse criança estrangeira aqui residente, apta a ser adotada, qual seria o caráter dessa adoção?

A necessidade de uma definição uniforme e fechada ainda não fora arguída como necessitava ser.

Em 1988, a Assembleia Nacional Constituinte brasileira promulgou a Constituição Federal que tratou da medida, sem defini-la, considerando a nacionalidade dos envolvidos. ${ }^{22}$

21 A adoção internacional, medida de caráter excepcional, passou a ser regulamentada no Brasil em 1979, pelo Código de Menores, promulgado nesse ano.

22 O artigo da Constituição de 1988 que se refere à adoção internacional é o art. 227. No $\S 5^{\circ}$. encontra-se a disposição relativa ao instituto no sentido da internacionalidade.

“Art. 227. É dever da família, da sociedade e do Estado assegurar à criança, ao adolescente e ao jovem, com absoluta prioridade, o direito à vida, à saúde, à alimentação, à educação, ao lazer, à profissionalização, à cultura, à dignidade, ao respeito, à liberdade e à convivência familiar e comunitária, além de colocá-los a salvo de toda forma de negligência, discriminação, exploração, violência, crueldade e opressão. .. 
Ao se referir à lei, no $\S 5^{\circ}$, do art. 227, o legislador constituinte fazia menção ao Código de Menores que vigorava nessa época, e que tratava da adoção internacional em um único artigo e mesclava conceitos, conforme já relatado.

A Constituição Federal deu destaque ao fato de que todas as crianças deveriam ter direito fundamental de conviver com sua família natural ou, em casos de perda, uma família substituta. A convivência na comunidade também tem previsão legal, mas as dificuldades são sanadas em pequena proporção, diante da miséria e caos social.

Em 1990, deu-se a revogação do Código de Menores, entrando em vigor o Estatuto da Criança e do Adolescente (ECA), lei 8.069 de 1990. O ECA passou a regulamentar o instituto da adoção, tanto em âmbito nacional quanto internacional, do art. 28 ao 31 e do art. 39 ao 52, ocupando-se da adoção internacional de forma reduzida, apenas nos art. 31 e $52 .{ }^{23}$

Não havendo maiores disposições a respeito do instituto no âmbito transnacional, os procedimentos para se obter a medida copiam os da adoção nacional.

Mais uma vez, o legislador referiu-se ao elemento nacionalidade, sem se preocupar com o local de residência. A preocupação com a adoção internacional não parecia relevante a ponto de exigir um maior cuidado em sua regulamentação. Ocorreu, porém, uma nova abordagem relativa à judicialização da medida, uma vez que o deferimento da adoção nacional competia ao Juiz da Infância e da Adolescência e o trâmite era o mesmo para as medidas de caráter internacional.

$\S 5^{\circ}$. A adoção será assistida pelo Poder Público, na forma da lei, que estabelecerá casos e condições de sua efetivação por parte de estrangeiro".

23 Assim estipulavam os artigos: Art. 31 do ECA: A colocação em família substituta estrangeira constitui medida excepcional, somente admissível na modalidade de adoção.

Art. 52. A adoção internacional poderá ser condicionada a estudo prévio e análise de uma comissão estadual judiciária de adoção, que fornecerá o respectivo laudo de habilitação para instruir o processo competente.

Parágrafo único. Competirá à comissão manter registro centralizado de interessados estrangeiros em adoção. 
Em 29 de maio de 1993, na Haia, foi concluída a Convenção Relativa à Proteção das Crianças e à Cooperação em Matéria de Adoção Internacional, e por meio do decreto $n^{\circ}$. 3.087, de 21 de junho de 1999, o texto da Convenção da Haia passou a fazer parte do complexo legislativo nacional.

A partir daí, uma definição de adoção internacional começou a ser sedimentada, tanto na doutrina quanto na legislação brasileiras. $\mathrm{O}$ elemento de conexão domicílio passou a ser o parâmetro para a conceituação, deixando-se de lado o elemento nacionalidade. ${ }^{24}$

A Convenção utiliza os termos Estado de origem e Estado de acolhida para designar o deslocamento da criança ou adolescente. Estado de origem é aquele onde está a residência habitual do adotando, e Estado de acolhida é o país onde residem os seus adotantes.

Em 10 de janeiro de 2002 foi promulgada a lei 10.406, o novo Código Civil, o qual não regulamentou a adoção internacional. Remeteu a disciplina ao Estatuto da Criança e do Adolescente, ECA, por meio do art. 1.629. ${ }^{25}$ Constata-se que as dificuldades de se sentenciar uma adoção internacional permaneciam, causando, nesse universo, incerteza, pouca segurança e intranquilidade por parte das autoridades competentes.

A adoção internacional tem sua sede no Direito Internacional, mas conta com o auxílio do Direito Civil e do Direito da Criança e do Adolescente. Manifesta-se, assim, a transdisciplinaridade, tão útil nas decisões atuais.

Para Jacob Dolinger (2003), o elemento de extraneidade presente na adoção internacional tanto pode ser a nacionalidade das partes ou o locus da realização da medida. Nesse sentido, deve ser estudada no Direito Internacional Privado. $\mathrm{O}$ autor afirma que o instituto será internacional quando nacionalidades e domicílios dos envolvidos não forem os mesmos. Numa visão atual, porém, direcionando-se a formulação do

24 O art. 2-1 da Convenção da Haia estatui: “Art. 2-1 A Convenção será aplicada quando uma criança com residência habitual em um Estado Contratante ("o Estado de origem") tiver sido, for, ou deva ser deslocada para outro Estado Contratante ("o Estado de acolhida"), quer após sua adoção no Estado de origem por cônjuges ou por uma pessoa residente habitualmente no Estado de acolhida, quer para que essa adoção seja realizada, no Estado de acolhida ou no Estado de origem”.

25 Art. 1.629. A adoção por estrangeiro obedecerá aos casos e condições que forem estabelecidos em lei. 
conceito para o que foi indicado pela Convenção da Haia sobre adoção, o elemento base para a conceituação é o território, no caso, o local do domicílio ou da residência habitual.

A nacionalidade deve ser desconsiderada para que se obtenha uma definição compatível com a matriz convencional. Mesmo com a transição da concepção contratualista da adoção para a da defesa dos interesses e garantias do adotando, a ideia central da definição na atualidade parece corresponder melhor à perspectiva da utilização do elemento territorial, ancorada no local de domicílio ou residência das partes, que não devem ser os mesmos. As modificações legislativas foram se adequando ao conceito instituído pela Convenção da Haia, gradativamente, apesar da mesma já ter sido internalizada no Brasil desde 1999. ${ }^{26}$

Nota-se que o ECA precisava de alguns ajustes nos dispositivos atinentes à adoção internacional, a fim de estabelecer a correta regulamentação do instituto. Basta observar que a referência à adoção internacional, disposta no art. 51, usava, concomitantemente, os dois elementos conectivos: nacionalidade e domicílio das partes. ${ }^{27}$

Em 2009, promulgou-se a Lei Nacional da Adoção, lei 12.010, de 3 de agosto desse ano, que harmonizou as normas estatuídas na Convenção da Haia de 1993 com o direito interno brasileiro vigente.

A citada lei, que modificou o ECA no que se referia à medida da adoção, estabeleceu o conceito de adoção internacional, referindo-se ao que fora criado pela Convenção da Haia sobre Adoção, por meio da modificação do art. 51, caput, do Estatuto. ${ }^{28}$

26 Diz Dolinger que: "Basicamente, teremos uma adoção internacional quando adotando e adotado têm nacionalidades diferentes ou domicílios diversos", o que não se coaduna atualmente com a diretriz legislativa brasileira, já que a nacionalidade não interfere na conceituação (DOLINGER, Jacob. Direito civil internacional: A criança no direito internacional. Rio de Janeiro: Renovar, 2003, p. 406).

27 Art. 51: Cuidando-se de pedido de adoção formulado por estrangeiro residente ou domiciliado fora do País, observar-se-á o disposto no art. 31.

28 O artigo em questão passou a ter a seguinte redação: ECA “Art. 51. Considera-se adoção internacional aquela na qual a pessoa ou casal postulante é residente ou domiciliado fora do Brasil, conforme previsto no Art. 2 da Convenção de Haia, de 29 de maio de 1993, Relativa à Proteção das Crianças e à Cooperação em Matéria de Adoção Internacional, aprovada pelo Decreto Legislativo ${ }^{\circ}$. 1, de 14 de janeiro de

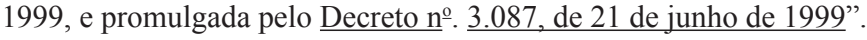


Apesar da definição ter sido atualizada, o próprio Estatuto, mesmo modificado, ainda mantém algumas distorções. No $\S 1^{\circ}$. do próprio art. 51, o legislador referiu-se à criança ou adolescente brasileiro. Da mesma forma ocorreu no inciso I do art. 52, em que há referência à pessoa ou casal estrangeiro. No final do inciso, porém, existe menção à residência habitual. ${ }^{29}$

A necessidade de uma uniformização terminológica não é um mero capricho textual e sim uma forma de se sanar juridicamente qualquer dúvida.

A adoção internacional precisa reunir como partes - adotantes e adotandos - pessoas com domicílio ou residência habitual em Estados diversos, quaisquer que sejam suas nacionalidades. ${ }^{30}$

A adoção internacional surge como alternativa para que crianças ou adolescentes no Brasil tenham a oportunidade de fazerem parte de uma família, da qual estão privados, por inúmeros motivos. Adotantes domiciliados em outros Estados parecem mais propícios a aceitar crianças de mais idade, de qualquer etnia, com dificuldades motoras ou emocionais ou grupos de irmãos. Várias instituições participam do procedimento para a concessão da medida. Assim, oportunidades reais de filiação surgem para essas crianças.

Na visão de Luís Renato Vedovato (2015), o elemento de conexão utilizado para as questões que transpõem barreiras territoriais é escolha de cada Estado, mas o domicílio tem força autêntica. ${ }^{31}$

29 Assim se lê nos artigos mencionados: Art. 51, § 1ํ A adoção internacional de criança ou adolescente brasileiro ou domiciliado no Brasil somente terá lugar quando restar comprovado: Artigo 52, I - a pessoa ou casal estrangeiro, interessado em adotar criança ou adolescente brasileiro, deverá formular pedido de habilitação à adoção perante a Autoridade Central em matéria de adoção internacional no país de acolhida, assim entendido aquele onde está situada sua residência habitual.

30 Guilherme de Mello Barros explica que: "Pela nova redação (do art. 51), a adoção é internacional quando o postulante é residente ou domiciliado fora do Brasil, independente da nacionalidade" (BARROS, Guilherme Freire de Melo. Estatuto da Criança e do Adolescente. Lei 8.069/1990. Salvador: Editora Jus Podium, 2010, p. 102).

31 O autor afirma que: "Atualmente, com o cenário mundial permeado por uma crescente interação transnacional, que se aprofunda com o incremento da tecnologia, especialmente a relativa a comunicações, as quais se tornam cada vez mais rápidas e acessíveis, o elemento de conexão é uma questão realmente de escolha do país, 
Florisbal Del'Olmo (2010) comenta a adoção internacional, referindo-se a esta como adoção por estrangeiros domiciliados fora do Brasil, apesar de mencionar a lei de 2009 que atualizou a medida. Pode-se dizer que quase a totalidade dos casos de residentes no exterior que pleiteiam a adoção de residentes no Brasil é de estrangeiros. Há na lição do autor a colocação dos dois critérios conjuntamente, o que não desmerece a abordagem, pois o próprio ECA utiliza os dois termos. De qualquer maneira, como entendido, o que caracteriza essa forma de adoção é a diversidade de territórios e não a nacionalidade das partes. ${ }^{32}$

O posicionamento categórico de Luciano Rossato e Paulo Eduardo Lépore (2009) não deixa dúvidas de que se deve seguir o marco conceitual estabelecido pela Convenção da Haia sobre Adoção. Os autores afirmam não ser a adoção internacional a realizada por estrangeiros, conforme durante algum tempo foi o posicionamento da lei e da doutrina brasileiras. Para os autores, o vínculo entre as partes se concretiza com a troca de domicílio da criança ou adolescente que reside no Brasil. ${ }^{33}$

Em conclusão, a adoção internacional, medida de colocação de crianças e adolescentes residentes no Brasil em famílias substitutas domiciliadas no exterior, é extremamente salutar, desde que seguidos todos os requisitos legais exigidos e o bom senso das autoridades envolvidas. O que se almeja será sempre o superior interesse do adotando.

Para Hugo Martins e Maria Walkíria Cabral (2016), a natureza

pois não se pode afirmar que haverá mais não domiciliados que não nacionais nessas relações jurídicas" (VEDOVATO, Luís Renato. A nacionalidade no direito internacional privado brasileiro: elemento de exclusão In: RAMOS, André de Carvalho [Org.]. Direito internacional privado: questões controvertidas. Belo Horizonte: Arraes Editores, 2015, p. 178).

32 DEL'OLMO, Florisbal de Souza. Curso de Direito Internacional Privado. Rio de Janeiro: Forense, 2010, p. 136.

33 Na opinião de Rossato e Lépore sobre a adoção transnacional: "Uma advertência deve ser feita: a adoção internacional, definitivamente, não é aquela efetivada por estrangeiros! Terá natureza de adoção internacional, segundo o Estatuto, aquela na qual a pessoa ou o casal postulante é residente ou domiciliado fora do Brasil (art. 51 do Estatuto) (ROSSATO, Luciano Alves; LÉPORE, Paulo Eduardo. Comentários à Lei Nacional da Adoção: Lei 12.010, de 3 de agosto de 2009 e outras disposições legais: Lei 12.003 e Lei 12.004. São Paulo: Revista dos Tribunais, 2009, p. 59). 
jurídica da adoção internacional sofre do mesmo dilema da adoção interna, mas é predominante seu caráter de instituto de ordem pública, justificado pela proteção constitucional à infância e a soberania nacional envolvida no instituto. ${ }^{34}$

Tarcísio Martins da Costa (2004) comenta que:

A adoção internacional é uma instituição jurídica de proteção e integração familiar de crianças e adolescentes abandonados ou afastados de sua família de origem, pela qual se estabelece, independentemente do fato natural da procriação, um vínculo de paternidade e filiação entre pessoas radicadas em distintos Estados: a pessoa do adotante com residência habitual em um país e a pessoa do adotado com residência habitual em outro. ${ }^{35}$

Desde as primeiras adoções internacionais, algumas regras têm sido observadas pelos especialistas e autoridades competentes que se conectam para a consecução da medida.

Na obra Abandono e adoção, Leila Cavallieri sugeria que, se fossem seguidos certos preceitos, a possibilidade de êxito do deferimento das adoções transnacionais seria consistente.

Inicialmente, só poderia deixar o país aquela criança ou adolescente cujas possibilidades de suas adoções internas fossem exauridas.

Em seguida, era necessário um completo estudo da família residente no exterior postulante da adoção. Isto incluiria um completo dossiê de sua vida pessoal, social, profissional, e até religiosa. Seus valores e princípios seriam avaliados e o resultado conclusivo seria do conhecimento da autoridade nacional.

34 MARTINS, Hugo Lázaro Marques; CABRAL, Maria Walkíria de Faro Coelho Guedes. Adoção internacional e o ordenamento jurídico brasileiro: uma breve reflexão sobre o seu caráter subsidiário. In: MENEZES, Wagner (Org.). Direito internacional em expansão. v. III. Anais do $\mathbf{1 2}^{\circ}$. Congresso Brasileiro de Direito Internacional. Belo Horizonte: Arraes, 2016, p. 407-415.

35 COSTA, Tarcísio José Martins da. Estatuto da Criança e do Adolescente Comentado. Belo Horizonte: Del Rey, 2004, p. 82. 
Também se fazia necessário que não se encontrasse qualquer vestígio de que pudesse haver interesse monetário envolvido.

Importante ressaltar que a autora dispunha que toda adoção, seja interna ou internacional, deveria, obrigatoriamente, submeter-se a controle judicial.

Outra sugestão relevante era no sentido de que a autoridade, que no Brasil deferisse a adoção internacional, conhecesse a lei que no país de acolhida fosse aplicada ao adotando. O objetivo seria evitar que leis estrangeiras pudessem causar danos à vida familiar, social e até política das crianças e adolescentes oriundos do Brasil.

Como corolário das proposições, devia ser alcançado o superior interesse dos adotandos, mandamento prioritário em qualquer situação. ${ }^{36}$

\section{A lei estrangeira e os obstáculos Para os adotandos no PAÍS DE DESTINO E SEUS DIREITOS FUNDAMENTAIS}

O conhecimento pelo juiz brasileiro das leis que serão aplicadas aos adotandos no país de acolhida é relevante e imprescindível. Alguns Estados possuem normativas bastante discriminatórias em relação àqueles que não são seus nacionais. Assim, quando as autoridades nacionais se confrontam com as expectativas dos adotandos perante suas futuras vidas jurídica, política e social percebem o quanto esse conhecimento é importante.

Dúvida alguma existe na constatação de que crianças ou adolescentes nascidos no Brasil são brasileiros natos, com exceção daqueles cujos pais estejam a serviço de seu país. Não é o caso, obviamente dos que estão abrigados em instituições de acolhimento, órfãos ou em situação de abandono.

Dessa forma, ao serem encaminhados ao Estado de residência de seus adotantes, lá chegarão como estrangeiros.

36 CAVALLIERI, Leila Arruda. Adoção Internacional. In: FREIRE, Fernando (Org.). Abandono e Adoção. Curitiba: Terre des Hommes, 1999. 
A questão pode tornar-se mais preocupante quando se tratar da aquisição ou perda de nacionalidade. Isto se explica pelo fato de que as crianças e adolescentes aqui nascidos e residentes são brasileiros natos e, portanto, considerados estrangeiros pelas autoridades do país de seus novos pais.

Se o país de acolhida não criar mecanismos eficazes para conceder a nacionalidade dos adotantes ou a estabelecida pelo Estado para os seus cidadãos aos adotandos, desde sua chegada, estes poderão enfrentar obstáculos que prejudicarão sua adaptação ao novo domicílio. ${ }^{37}$

Apresenta-se questão grave o bastante para preocupar de forma abrangente os Estados que atuam nas adoções internacionais. A pessoa sem nacionalidade, apátrida, não possui qualquer proteção específica dos Estados, fato especialmente sério em se tratando de épocas de comoções sociais e guerras, situações que por si só já podem causar a perda de nacionalidade. ${ }^{38}$

Grande parte dos países da Europa tem programas assistenciais e educacionais destinados a crianças e adolescentes que fazem parte de sua população e que ostentam a nacionalidade do país.

Se o adotando é nascido no Brasil, pode perder vários desses benefícios ou direitos, que via de regra são concedidos aos natos.

No tocante à adoção internacional, verifica-se que alguns Estados adotaram medidas para garantir aos adotandos, residentes em países diferentes daqueles onde residem os adotantes, direitos atinentes à nacionalidade.

37 Del'Olmo (2015) se refere ao caso de brasileiros que podem ter duas nacionalidades primárias, uma pelo ius soli, no caso das crianças aqui nascidas e outra pelo ius sanguinis e isso independe de sua vontade ou de seus pais. Pode ocorrer pelo registro civil ou outro procedimento administrativo equivalente, que é o caso previsto em algumas leis por força da adoção internacional.

38 O Brasil ratificou o Estatuto dos Apátridas, da ONU de 1995, por meio do Decreto $4.246 / 2002$. Considerando a condição de vulnerabilidade daqueles que não são reconhecidos como nacionais de país algum é que se avalia quão essencial é ter uma nacionalidade e toda proteção e direitos que ela propicia. É um sinal da preocupação mundial com as pessoas que perdem um de seus direitos fundamentais. 
Seu direito fundamental a uma nacionalidade está garantido pela Constituição Federal, mas é necessário que não ocorra a perda do mesmo no país dos adotantes. E ainda mais, que se garanta a aquisição da nacionalidade dos seus novos pais, na condição de natos. O status jurídico dessas crianças será de detentores de dupla nacionalidade.

No Brasil, a Autoridade Central determinada pela Convenção da Haia é a ACAF, Autoridade Central Administrativa Federal, que atua com as Comissões de Adoção Internacional, as CEJAIs. ${ }^{39}$

São as famílias residentes ou domiciliadas na Itália as que mais procuram o Brasil para adotar as crianças daqui. Das 189 adoções internacionais realizadas no Rio de Janeiro, do ano de 2009 a 2016, 149 envolveram famílias domiciliadas na Itália, segundo o Portal da Infância e da Juventude. ${ }^{40}$

\section{SoluÇões Adotadas PEla Lei ITALIANA PARA GARANTIR O DI- REITO FUNDAMENTAL À NACIONALIDADE}

É por meio do número 3, do art. 34 da lei 476 de $1998,{ }^{41}$ que o legislador italiano estabeleceu, a respeito da aquisição da cidadania italiana pelos adotandos residentes no Brasil e que foram deslocados para a Itália, que a transcrição do ato adotivo nos registros civis italianos que essas crianças e adolescentes passam a ser italianos.

Além disso, a Itália não exige que renunciem à nacionalidade brasileira, portanto, os adotandos podem usufruir dos direitos e exercer as obrigações de ambas as nacionalidades.

39 O Tribunal de Justiça do Estado do Rio de Janeiro, com a CEJAI, elaborou uma cartilha denominada Amor sem Fronteiras, com instruções e relatos de processos de adoção internacional. A cartilha informa que os pretendentes habilitados pelos organismos credenciados, ao chegarem ao Rio de Janeiro, são recebidos e atendidos pela equipe técnica da CEJAI/RJ para esclarecimentos e orientações acerca da adoção e dos procedimentos do estágio de convivência. Comissão Estadual Judiciária de Adoção Internacional - CEJAI - RJ. Amor sem Fronteiras. Rio de Janeiro: Gráfica do Tribunal de Justiça do Estado do Rio de Janeiro, 2014.

40 Disponível: $<$ http://infanciaejuventude.tjrj.jus.br/cejai/estatistica.html $>$.

41 A lei 476/98 dispõe no art. 34 que: "3. O menor adotado adquire a cidadania italiana por efeito da transcrição da medida de adoção nos registros de estado civil”. 
Para a residência na Itália, junto à sua nova família, a efetividade do exercício dos direitos concedidos por meio da cidadania italiana tem um imenso potencial emancipatório. É por intermédio deles que a integração ampla dos adotandos aos lares adotivos se fará de forma mais célere e se conquistará, num grau elevado, a manutenção do alicerce satisfatório de um direito fundamental.

Dessa forma, basta que se transcreva em repartição competente italiana a sentença de adoção para que, de imediato, essas crianças e adolescentes se tornem italianos, continuando, porém, a ostentar a nacionalidade brasileira.

O processo de adoção internacional na Itália é rigoroso e demorado, como se espera que seja em qualquer país para que a medida se concretize, iniciando-se pela declaração de disponibilidade dos adotantes de acordo com o art. 29-bis, 1, da lei n ${ }^{\circ}$. 149/2001. Os postulantes precisam ir ao Tribunal de Menores competente, no local de seu domicílio, para manifestarem sua intenção de adotar uma criança que tenha sua residência habitual em outro país.

A partir do recebimento da autoridade local de um certificado de idoneidade, expedido após a comprovação de que todos os requisitos estão cumpridos, a família adotante italiana inicia o processo de adoção, propriamente dito.

Esse processo de averiguação de casais ou famílias é invasivo e delicado, nem sempre aceito com a tolerância necessária pelos adotantes. As entidades locais atuam na pesquisa intensamente para que os postulantes sejam realmente considerados como a família ideal para a criança ou adolescente que serão adotados, declarando sua idoneidade.

De acordo com a lei italiana, o casal interessado na adoção internacional, obrigatoriamente, tem que realizar contato com uma agência especializada em intermediar as adoções internacionais. ${ }^{42}$

42 O Brasil tem cerca de 20 agências credenciadas, sendo a maioria italiana. São elas: AAiM - ASSOCIACIÓ D’AJUDA ALS INFANTS DEL MÓN; AFN - AZIONE PER FAMIGLIE NUOVE; AiBi - ASSOCIAZIONE AMICI DEI BAMBINI; AIPA - ASSOCIAZIONE ITALIANA PRO ADOZIONE; AMI - AMICI MISSIONI INDIANE; APC - COFA COGNAC; ARAI PIEMONTE - Agenzia Regionale Per 
São essas entidades ou agências que instruem os futuros pais visando a que se preparem para o que lhes reserva a medida, inclusive em relação ao prazo. Não se pode ser impaciente, pois todo o trâmite procedimental deve ser seguido e respeitado para que o instituto se concretize de forma definitiva, segura e lícita.

A lei italiana 476, de 31 de dezembro de 1998, publicada em 8 de janeiro de 1999, no Diário Oficial italiano - Gazzetta Ufficiale, n. 8, contemplou a situação com lucidez e comprometimento necessários, pois a questão envolve partes que passam por momentos de tensão e dúvidas durante todo o processo adotivo.

Dessa feita, estabeleceu que o filho adotado internacionalmente por italianos obterá a cidadania italiana por meio do registro da sentença de adoção nas repartições italianas competentes. A partir desse ato, a cidadania é definitiva.

A certidão de nascimento do adotando, expedida pelo cartório brasileiro por exigência do Juiz da Infância e Juventude, é apresentada à autoridade italiana e arquivada em repartição própria.

Na Itália, a Comissão de Adoções Internacionais denomina-se Cai e não se medem esforços para uma melhoria da rede de instituições e profissionais que atuam para concretizar o instituto da melhor forma. Existe uma preparação bastante longa dessas pessoas, de forma interprofissional e interdisciplinar.

Jesús Palacios (2016) explica que a complexidade e importância de se proteger as crianças e adolescentes aparece em destaque na ado-

Le Adozioni Internazionali; ATWA - ACROSS THE WORLD ADOPTION; ASSOCIAÇÃO ARC EN CIEL FRANCE; ASSOCIAÇÃO PROGETTO SÃO JOSÉ; AVSI -ASSOCIAZIONE VOLONTARI PER IL SERVIZIO INTERNAZIONALE; BRADOPTA; CIFA - CENTRO INTERNAZIONALE PER L'INFANZIA E LA FAMIGLIA; HAND IN HAND INTERNACIONAL ADOPTIONS; I CINQUE PANI; IL MANTELLO - ASSOCIAZIONE DI VOLONTARIATO PER LA FAMIGLIA E L'ADOZIONE; LIFELINE CHILDREN'S SERVICE; LUTHERAN SOCIAL SERVICE OF MINNESOTA; MÉDECINS DU MONDE; NOVA-NUOVI ORIZZONTI PER VIVERE LA ADOZIONE; RETE SPERANZA ONLUS; SENZA FRONTIERE ONLUS. 
ção. ${ }^{43} \mathrm{O}$ autor expõe sua preocupação em relação a níveis inevitáveis de incertezas no que diz respeito ao êxito do instituto.

Havendo um alto grau de especialização dos profissionais e ações no sentido de se buscar sempre o superior interesse da criança, as possibilidades de que tudo dê certo são imensas.

Paola Loddo (2017) acentua que as relações criadas pela adoção internacional são sedimentadas aos poucos, estabelecendo a confiança recíproca no sentido da busca da felicidade da família. ${ }^{44}$

Sabe-se que outros países têm legislação semelhante e se augura que a iniciativa legal se irradie por todos os Estados nos quais se contempla a adoção internacional, onde a busca da família ideal para uma criança ou adolescente é a prioridade.

\section{Considerações FinAis}

Os Estados têm o dever de assegurar aos seus nacionais a proteção necessária para que usufruam de uma vida digna e em conformidade com os preceitos estipulados em sua legislação de base. Não há taxatividade em sua enumeração, portanto, a qualquer momento um direito pode ser entendido e interpretado como fundamental.

A delimitação desses direitos pode variar de Estado para Estado, o que dificulta, muitas vezes, sua proteção internacional. Para a proteção e garantia do exercício dos direitos em âmbito transnacional, é necessário que os Estados cumpram as normativas presentes nos tratados e convenções a que aderiram.

A criação de organizações com esse intuito protetivo também

43 PALACIOS, Jesus. Il processo decisionale per la tutela dei minori. Minorigiustizia, Rivista trimestrale interdisciplinare di studi giuridici, psicologici, pedagogici e sociali sulla relazione fra minorenni e giustizia, Milão: Franco Angeli, n. 4, 2016, p. 145.

44 Diz a autora que: "I genitori adottivi sembrerebbero sviluppare una maggiore fiducia e sicureza in se stessi e nella relazione con il minore, migliori capacità di comunicazione con il figlio". LODDO, Paola. Il punto di vista della famiglia di origine. Minorigiustizia, Rivista trimestrale interdisciplinare di studi giuridici, psicologici, pedagogici e sociali sulla relazione fra minorenni e giustizia, Milão: Franco Angeli, n. 1, 2017, p. 65. 
opera positivamente na medida em que denunciam os abusos e tentam interrompê-los e compensá-los.

Os poderes estatais devem, em conjunto, propiciar ao cidadão o conhecimento dos canais mais céleres para evitar a ação erosiva de medidas que possam levar ao atingimento dos direitos que fundamentam a vida e a liberdade dos indivíduos.

Dessa feita, pode-se considerar que, na aferição da medida adotiva de cunho internacional, os direitos à convivência familiar e comunitária e, o de possuir um vínculo de cidadania e nacionalidade com um Estado são fundamentais e devem ser garantidos por meio estatal.

Por meio da adoção internacional, crianças e adolescentes residentes no Brasil podem tirar proveito da companhia da família residente no exterior que os adotou, com ela convivendo, sendo protegido, amado e respeitado, já que não foi possível sua inserção em família substituta brasileira.

Quando se fortalece o entendimento de que o elo entre a pessoa e determinado Estado, por meio da nacionalidade, é parte dos valores que se oferecem a ela, a aquisição e exercício desse valor têm plena garantia.

A nacionalidade, seja entendida como nata ou adquirida, objetiva a residência, o trabalho, a aquisição de cultura e demais direitos a ela inerentes.

Portanto, estabelecer formas de se garantir aos adotandos aqui residentes a possibilidade de obter a nacionalidade do país para o qual serão encaminhados, deve ser uma tarefa contínua, séria e indispensável exercida pelos Estados envolvidos na adoção internacional, com respaldo na legislação interna e na doutrina alicerçada em posicionamentos de especialistas na matéria.

\section{REFERÊNCIAS}

BARROS, Guilherme Freire de Melo. Estatuto da Criança e do Adolescente. Lei 8.069/1990. Salvador: Editora Jus Podium, 2010. 
BRANCO, Paulo Gustavo Gonet. In: MENDES, Gilmar Ferreira; COELHO, Inocêncio Mártires; BRANCO, Paulo Gustavo Gonet. Teoria Geral dos Direitos fundamentais. Curso de Direito Constitucional, 4. ed. rev. e atual. São Paulo: Saraiva, 2009.

BRITTO, Lemos. As leis de menores no Brasil. Rio de Janeiro: F. Briguiet e Cia., 1929.

CAVALliERI, Alyrio. Direito do Menor, 2. ed. Rio de Janeiro: Freitas Bastos, 1978.

CAVALLIERI, Leila Arruda. Adoção Internacional. In: FREIRE, Fernando (Org.). Abandono e Adoção. Curitiba: Terre des Hommes, 1999.

O Direito Internacional e a Criança. Adoção Transnacional e Nacionalidade do Adotando. Belo Horizonte: Arraes Editores Ltda., 2017.

COSTA, Tarcísio José Martins da. Estatuto da Criança e do Adolescente Comentado. Belo Horizonte: Del Rey, 2004.

DEL'OLMO, Florisbal de Souza. A releitura da perda da nacionalidade brasileira nata à luz do caso Claudia Hoerig In: RAMOS, André de Carvalho (Org.). Direito internacional privado: questões controvertidas. Belo Horizonte: Arraes Editores, 2015.

. Curso de Direito Internacional Privado. Rio de Janeiro: Forense, 2010.

DOLINGER, Jacob. Direito civil internacional: A criança no direito internacional. Rio de Janeiro: Renovar, 2003.

LODDO, Paola. Il punto di vista della famiglia di origine. Minorigiustizia, Rivista trimestrale interdisciplinare di studi giuridici, psicologici, pedagogici e sociali sulla relazione fra minorenni e giustizia. Milão: Franco Angeli, n. 1, 2017.

MARTINS, Hugo Lázaro Marques; CABRAL, Maria Walkíria de Faro Coelho Guedes. Adoção internacional e o ordenamento jurídico brasileiro: uma breve reflexão sobre o seu caráter subsidiário. In: MENEZES, Wagner (Org.). Direito internacional em expansão, v. III. Anais do $\mathbf{1 2}^{\mathbf{0}}$. Congresso Brasileiro de Direito Internacional. Belo Horizonte: Arraes, 2016.

MELLO, Celso D. de Albuquerque. Curso de Direito Internacional Público. Rio de Janeiro: Renovar, 2001. 
PALACIOS, Jesus. Il processo decisionale per la tutela dei minori. Minorigiustizia, Rivista trimestrale interdisciplinare di studi giuridici, psicologici, pedagogici e sociali sulla relazione fra minorenni e giustizia. Milão: Franco Angeli, n. 4, 2016.

ROSSATO, Luciano Alves; LÉPORE, Paulo Eduardo. Comentários à Lei Nacional da Adoção: lei 12.010, de 3 de agosto de 2009 e outras disposições legais: Lei 12.003 e Lei 12.004. São Paulo: Revista dos Tribunais, 2009, p. 59.

SARLET, Ingo. A eficácia dos direitos fundamentais. Porto Alegre: Livraria do Advogado, 1998.

SARMENTO, Daniel. A Dimensão Objetiva dos Direitos Fundamentais: Fragmentos de uma Teoria. In: Arquivos de Direitos Humanos. Rio de Janeiro: Renovar, 2002.

SOUZA NETO, Cláudio Pereira. Fundamentação e Normatividade dos Direitos Fundamentais: Uma Reconstrução Teórica à Luz do Princípio Democrático. In: Arquivos de Direitos Humanos. Rio de Janeiro: Renovar, 2002.

VEDOVATO, Luís Renato. A nacionalidade no direito internacional privado brasileiro: elemento de exclusão In: RAMOS, André de Carvalho (Org.). Direito internacional privado: questões controvertidas. Belo Horizonte: Arraes Editores, 2015.

\section{Sobre a autora}

Leila Arruda Cavallieri

Doutora em Direito pelas Universidades Gama Filho e Veiga de Almeida UGF/UVA - Rio de Janeiro. Mestre em Direito pela Universidade Gama Filho - UGF - Rio de Janeiro. Bacharel em Direito pela Pontifícia Universidade Católica - PUC - Rio de Janeiro. Professora de Direito Internacional Privado, Professora de Introdução ao Direito, Professora de Direitos da Criança e do Adolescente, Membro do Grupo de Pesquisa da Conferência da Haia, PUC-RJ, Membro da Asociación Americana de Derecho Internacional Privado (ASADIP), Membro da Rede Brasileira de Pesquisadores em Direito Internacional, Membro da International Law Association - ILA Brasil.

E-mail: leilacavallieri@gmail.com

Submetido em: 14-08-2017

Aceito em: 23-10-201 